\title{
O DISPOSITIVO PEDAGÓGICO DO CURRÍCULO-BRINQUEDO DE MATEMÁTICA, MARCADO PELA DIMENSÃO DE GÊNERO, NA PRODUÇÃO DE SUBJETIVIDADES
}

\author{
PEDAGOGIC DEVICE OF THE MATHEMATICS CURRICULUM-TOY MARKED BY GENDER DIMENSION IN THE PRODUCTION \\ OF SUBJECTIVITIES
}

\author{
EL DISPOSITIVO PEDAGÓGICO DEL CURRÍCULO-JUGUETE DE MATEMÁTICAS MARCADO POR LA DIMENSIÓN DE GÉNERO \\ EN LA PRODUCCIÓN DE SUBJETIVIDADES
}

\author{
SOUZA, Deise Maria Xavier de Barros ${ }^{1}$ \\ SILVA, Marcio Antonio²
}

\section{RESUMO}

Neste artigo, problematizam-se imagens dos livros didáticos de matemática dos anos iniciais utilizadas para a produção e normatização de um currículo-brinquedo e que podem indicar algum tipo de interação criança-brinquedo. Interroga-se, dentro de um referencial contemporâneo, por intermédio do pensamento de Michel Foucault e de contribuições dos Estudos Culturais, o currículo de matemática na produção de subjetividades unificadas de padrões socialmente construídos de gênero nas relações conflituosas entre saber, cultura e poder. Argumenta-se que, em meio ao movimento da cientificidade dos conhecimentos matemáticos, o currículo-brinquedo produz gestos múltiplos: uma pedagogia cultural que mascara a produção de subjetividades na infância; uma prática de diferenciação localizada nas representações de gêneros, como objeto para fixar identidades e regular a conduta de uns em relação a outros; e uma estratégia neoliberal para regular um dispositivo pedagógico no currículo.

Palavras-chave: Currículo; Sujeito. Subjetividade. Gênero. Dispositivo Pedagógico.

\section{ABSTRACT}

The article discusses images of mathematics textbooks of the primary grade used for the production and the standardization of a curriculum-toy, which may indicate some kind of child-toy interaction. In a contemporary frame through of Michel Foucault's thought and contributions of cultural studies, curriculum of mathematics in the production of unified subjectivity of gender socially constructed patterns in relations conflict between knowledge, culture and power is questioned. It is argued that, amid the movement of scientific theories of mathematical knowledge, curriculum-toy produces multiple gestures: a cultural pedagogy that masks the production of subjectivities in childhood; a practice of differentiation in the genres, such as object representations to secure identities and regulate the conduct of some other; and, a neoliberal strategy to regulate a pedagogical device in the curriculum. Keywords: Curriculum. Subject. Subjectivity. Gender. Pedagogical Device.

\section{RESUMEN}

El artículo analiza imágenes de libros de texto de matemáticas de los primeros años de clase, utilizadas para la producción y estandarización de un currículo-juguete y que pueden indicar algún tipo de interacción juguete-niño. El currículo de matemáticas en la producción de subjetividad unificada de los patrones socialmente construidos de género en las relaciones de conflicto entre conocimiento, cultura y poder es interrogado en un marco contemporáneo a través del pensamiento de Michel Foucault y las contribuciones de los Estudios Culturales. Se argumenta que, en medio de la circulación de las teorías científicas del conocimiento matemático, el currículo-juguete produce gestos múltiples: una pedagogía cultural que simplifica la producción de subjetividades en la infancia; una práctica de diferenciación ubicada en representaciones de los géneros, tales como objeto a fijar identidades y regular la conducta de unos en relación de otros; y una estrategia neoliberal para regular un dispositivo pedagógico en el currículo.

Palabras clave: Currículo. Sujeto. Subjetividad. Género. Dispositivo Pedagógico.

\footnotetext{
1 Universidade Federal de Mato Grosso do Sul - UFMS - Campo Grande - Mato Grosso do Sul - Brasil.

2 Universidade Federal de Mato Grosso do Sul - UFMS - Campo Grande - Mato Grosso do Sul - Brasil.
} 


\section{INTRODUÇÃO}

Este artigo é parte de uma tese de doutorado, em andamento, que interroga marcas de gênero no currículo de matemática dos anos iniciais do ensino fundamental. Em (SOUZA; SILVA, 2017), problematizamos alguns exemplos de como o currículo de matemática dos anos iniciais endereça condutas heteronormativas articuladas ao conhecimento matemático.

Neste artigo, a tarefa do movimento das análises é percorrer o campo do saber das representações normativas que cercam o cotidiano de meninos e meninas, sobretudo na escola, em uma existência rodeada de brinquedos e brincadeiras circunscritas por endereçamentos de gênero.

No campo da Educação há um forte discurso de que os brinquedos, as brincadeiras, os jogos, a ludicidade e o lúdico têm um papel importante para tornar o ambiente escolar mais envolvente e fascinante, a fim de melhorar o ensino e a aprendizagem das crianças. Grando (2000), por exemplo, desenvolve uma tese, muito citada no campo da Educação Matemática, defendendo que o trabalho pedagógico baseado em jogos pode minimizar "o hiato existente entre as atividades lúdicas cotidianas realizadas pelas crianças, espontaneamente, e o trabalho desencadeado em sala de aula" (p. 6). Em contrapartida, ainda no campo da Educação Matemática, há trabalhos (SARTORI; DUARTE, 2015; 2017) que problematizam marcas discursivas que envolvem o lúdico, indicando, entre outras questões, que "no discurso lúdico o sujeito está sendo produzido em consonância com o dispositivo neoliberal" (SARTORI; DUARTE, 2017, p. 66-67).

A partir desse cenário, problematizamos imagens dos livros didáticos de matemática dos anos iniciais que podem indicar algum tipo de interação criança-brinquedo, utilizadas para a produção e normatização de um currículo-brinquedo. Desse modo, usando um referencial social contemporâneo, interrogamos o currículo de matemática na produção de subjetividades unificadas.

Defendemos a tese de que as imagens e os textos do currículo de matemática não são utilizados em uma perspectiva que busca somente ensinar conhecimentos matemáticos. As imagens e textos movimentam um cenário sedutor do currículo de matemática para captar a atenção das crianças, encantando-as para o aprendizado, por intermédio de uma suposta contextualização que tem, pelo menos hipoteticamente, uma relação direta com as atividades cotidianas, no caso, as brincadeiras. Um currículo-brinquedo que opera uma alquimia (POPKEWITZ, 2004) e transforma crianças em meninos e meninas.

As imagens lúdicas, naturalizadas do mundo de meninos e meninas no currículo-brinquedo, são pedagogizadas como algo que se pode aprender a fazer, externa aos sujeitos da ação, definindo as posições e as funções que cada um pode ocupar no currículo de matemática ou na vida cotidiana. Essas imagens funcionam como saberes que indicam o domínio de cada brinquedo e brincadeira, delimitando o espaço em que cada criança "pode tomar posição para falar dos objetos de que se ocupa" (FOUCAULT, 2013, p. 220) ou ainda, indicam a coordenação e a subordinação dos conceitos do currículo-brinquedo, pois eles "aparecem, se definem, se aplicam e se transformam" (id. ib., p. 220). Enfim, problematizar um saber que articula o currículo de matemática às imagens da cultura dos 
brinquedos e brincadeiras naquilo que produzem na formação de subjetividades infantis. Um saber que se constitui por possibilidades de utilização e de apropriação de uma vida fora da escola.

Consideramos que as imagens e textos do currículo-brinquedo, marcados pela dimensão de gênero, funcionam dentro do sistema discursivo do conhecimento matemático, reivindicando o status de verdade,

os mecanismos e as instâncias que permitem distinguir os enunciados verdadeiros dos falsos, a maneira como se sanciona uns e outros; as técnicas e os procedimentos que são valorizados para a obtenção da verdade; o estatuto daqueles que têm o encargo de dizer o que funciona como verdadeiro (FOUCAULT, 2015, p. 52).

Em nosso tempo, a verdade sobre os sujeitos marcados pela dimensão de gênero é regida por uma economia política com características historicamente construídas. A verdade sobre ser menino ou menina no currículo de matemática está

[...] centrada na forma do discurso científico e nas instituições que o produzem; está submetida a uma constante incitação econômica e política (necessidade de verdade tanto para a produção econômica, quanto para o poder político); é objeto, de várias formas, de uma imensa difusão e de um imenso consumo (circula nos aparelhos de educação ou de informação, cuja extensão no corpo social é relativamente grande, não obstante algumas limitações rigorosas); é produzida e transmitida sob o controle, não exclusivo, mas dominante, de alguns grandes aparelhos políticos ou econômicos (universidade, exército, escritura, meios de comunicação); enfim, é objeto de debate político e de confronto social (as lutas "ideológicas") (FOUCAULT, 2015, p. 52).

As normatizações que qualificam os corpos de meninos e meninas no currículo de matemática, por meio de um sistema discursivo de gênero normativo, nas representações de brinquedos e brincadeiras, pressupõem e impõem a restrição do gênero preso a um par binário (BUTLER, 2016). Circula como verdade possível de ser articulada ao conhecimento científico da matemática escolar, onde são definidas regras, segundo as quais são induzidas certas formas de subjetividades no marcador de gênero. Assim, o currículo de matemática multiplica efeitos de subjetividades.

Problematizamos o currículo-brinquedo, suspendendo as relações da linguagem do ponto de vista do significado e do significante - uma relação direta entre imagens e significados, para descrever e analisar práticas discursivas de gênero no currículo de matemática. Práticas discursivas compreendidas como "um conjunto de regras anônimas, históricas, sempre determinadas no tempo e no espaço" (FOUCAULT, 2013, p. 144). Um tempo histórico que define as regras e as condições de marcas de gênero no currículo-brinquedo, como uma prática cultural discursiva considerada, no contexto dos Estudos Culturais, como um processo de significação, um "artefato social submetido a permanentes tensões e conflitos de poder" (VEIGA-NETO, 2000, p. 40). Com isso, as marcas de gênero são problematizadas nas relações conflituosas de poder do currículo dos anos iniciais, no centro das significações e identidades culturais, articulando o pensamento de Michel Foucault aos Estudos Culturais.

Nesse contexto, o movimento de análises de práticas discursivas de gênero no currículo de matemática implica uma dupla tarefa. Primeiro, considerar que o currículo de matemática pode mobilizar um conjunto de estratégias que fazem parte de práticas sociais produtoras de subjetividades, como nas representações de brinquedos e brincadeiras que são articuladas ao currículo. E, ainda, a de 
que o currículo de matemática produz uma verdade sobre o jogo das representações de gênero, o lugar onde se formam certo número de regras desse jogo, onde "se vê surgirem certas formas de subjetividade, certos domínios de objeto, certos tipos de saber" (FOUCAULT, 2014, p. 133) nas brincadeiras possíveis. Essa dupla tarefa nos movimenta por diferentes territórios de pesquisa, problematizando as fronteiras das áreas de pesquisa (SILVA; MIARKA, 2017) e possibilitando a nós um livre trânsito pelas áreas dos [E]estudos [C]culturais, da [E]educação [M]matemática, da [E]educação, da [F]filosofia, do [C]currículo, entre outras.

Trata-se de um combate contra o estatuto da verdade movimentada no currículo de matemática sobre os sujeitos marcados pela dimensão de gênero e sobre outros silenciados. Um combate local e específico, mas que pode acarretar efeitos em regimes de verdade de como podemos ser e agir e como deixamos o currículo de matemática agir sobre nossos corpos e quem sabe, pensarmos novas formas de ser e estar no mundo. Questionar o currículo de matemática na produção de subjetividades excludentes é um movimento de recusa a produção de individualidades heterossexuais oposicionais que a muito nos foi imposta e o currículo de matemática se mantém discursivamente, na margem dessa discussão, pois se firma como conhecimento neutro, desarticulado da produção de subjetividades.

Em Fonseca e Souza (2010) encontramos um indicativo do que as pesquisadoras chamam de silenciamento de estudos que problematizam questões de gênero na produção acadêmica da Educação Matemática brasileira. Isso, apesar de as pesquisadoras considerarem a "fertilidade desse conceito para analisar fenômenos e questionar posições e procedimentos que se forjam no reconhecimento de que nossas práticas pessoais e profissionais são sempre produtoras de gênero" (FONSECA; SOUZA, 2010, p. 27).

Em contrapartida, no campo da Educação Matemática internacional, pesquisas que tomam gênero como objeto de análise têm crescido substancialmente. Na década de 1990, pesquisadoras como Gilah Leder desenvolveram investigações tendo as reivindicações feministas como referência. Em um número especial da revista Educational Studies in Mathematics, Leder (1995) menciona a influência de movimentos da terceira onda feminista nas pesquisas desenvolvidas naquela época. Alguns anos antes, em 1993, ocorreu, na cidade de Höör (Suécia) um evento organizado pelo ICMI (International Commission on Mathematical Instruction), intitulado "Gênero e Educação Matemática". Esse evento histórico gerou a publicação de um livro, editado por Gila Hanna (HANNA, 1996), que se tornou referência na área e que, definitivamente, inseriu a temática de gênero na pauta de discussão de eventos da área.

Desde então, as pesquisas mudaram muito, passando das reivindicações por igualdade de gênero, sobretudo feitas por intermédio de estudos que apontavam as desvantagens das mulheres em relação aos homens, até as mais recentes pesquisas que problematizam os binarismos daquela época e tomam o gênero como uma construção que "leva em consideração maneiras de pensar e atuar disponibilizadas e geradas nas práticas físicas, sociais, culturais, discursivas e históricas das comunidades organizadas em torno de categorias fixas de identidade" (WALSHAW, et al., 2017, p. 185, tradução nossa). 


\title{
PRÁTICA DISCURSIVA DO BRINCAR NO CURRÍCULO
}

O currículo se constitui em um espaço profícuo para a produção de subjetividades, repetidas e, essencialmente presas em uma narrativa biológica: meninos e meninas, por meio de discursividades do brincar, uma vez que passam grande parte de seu tempo na escola, com no mínimo, 800 horas anuais ou o equivalente a 200 dias letivos (BRASIL, 1996).

A função do brinquedo, segundo Agamben (2005), representa mais do que resgatar uma relação de vizinhança e de legalidade com eventos do passado, que leva ao longo do tempo o caráter prático da coisa em si.

\begin{abstract}
O brinquedo é uma materialização da historicidade contida nos objetos, que ele consegue extrair por meio de uma manipulação particular. Enquanto, na verdade, o valor e o significado do objeto antigo ou do documento é função da sua antiguidade, ou seja, do seu presentificar e tornar tangivel um passado mais ou menos remoto, o brinquedo, desmembrando e distorcendo o passado ou miniaturizando o presente (AGAMBEN, 2005, p. 87).
\end{abstract}

Com isso, tanto o brinquedo como o brincar podem ser considerados como práticas discursivas internas a estrutura dos textos curriculares, dos anos iniciais do ensino fundamental, que abrem espaço para orientações, nos manuais dedicados aos professores, sobre jogos, brincadeiras ou o que chamam de "atividades lúdicas": "brincar é o ofício da criança: os jogos e as brincadeiras despertam o interesse dos alunos, pois os levam a enfrentar desafios, simulando situações reais da vida" (LONGEN, 2014, p. 360). No entanto, o brincar é a miniaturização do que é ser menino ou menina no tempo presente e de certa forma, contribui para assegurar práticas sociais e, portanto, culturais, que "expressam ou comunicam um significado e, neste sentido, são práticas de significação" (HALL, 1997, p. 16) movimentadas no currículo de matemática.

Como prática discursiva, as orientações aos professores que ensinam matemática nos anos iniciais, determinam sistematicamente o currículo-brinquedo nos 103 manuais de professores das coleções aprovadas no Plano Nacional do Livro Didático (PNLD) de 2016 sendo, 69 manuais de alfabetização matemática ( $1^{\circ} ; 2^{\circ}$ e $3^{\circ}$ anos) e, 34 de matemática ( $4^{\circ}$ e $5^{\circ}$ anos) que foram analisadas e qualificam a existência de uma regra a que estão submetidos - o de fazer brincar o currículo de matemática articulado as representações de gênero. Foram identificadas 528 figuras relacionadas às tarefas matemáticas, nas quais havia alguma interação entre crianças e brinquedos.

A prática discursiva do brincar no currículo de matemática envolve cenas da vida cotidiana, naturalizadas e materializadas nos objetos, no conhecimento matemático ou nas tarefas realizadas por imagens que referenciam sujeitos do feminino e do masculino que de alguma forma, servem para confirmar o currículo-brinquedo-de-matemática. 
Figura 1 - Mais tempo para brincar.

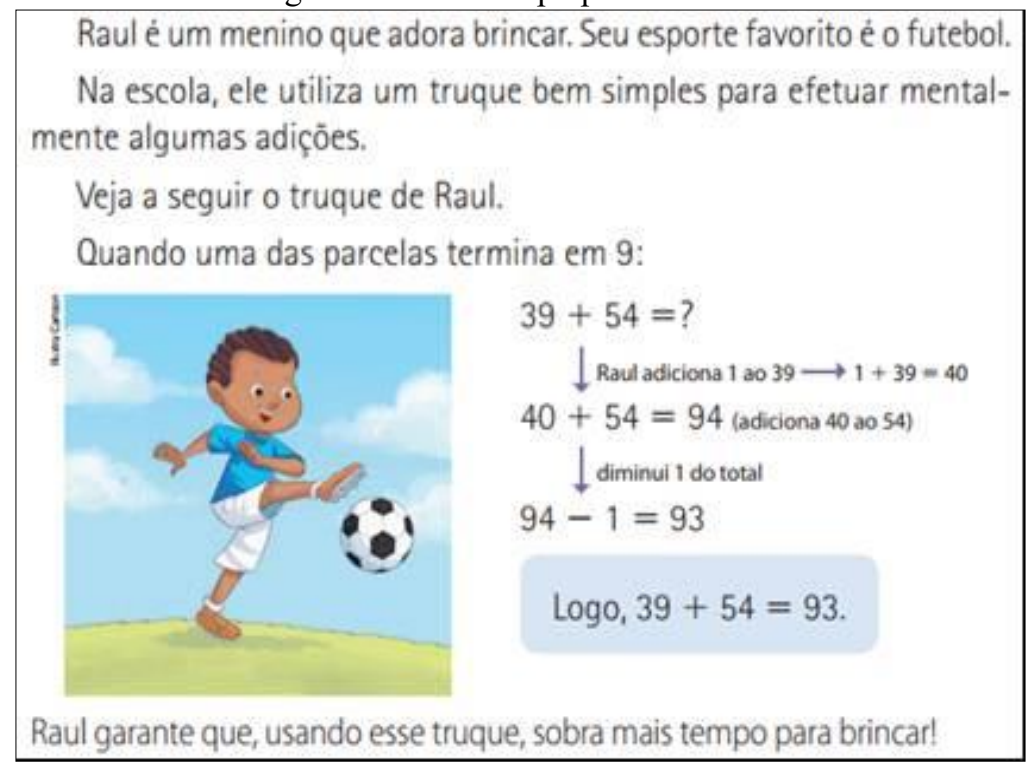

Fonte: Longen, 2014, p. 151.

O conhecimento, submetido ao "truque" do sujeito masculino no jogo da matemática que ganha mais tempo para brincar, fica em segundo plano. Mas, é o conhecimento matemático que faz a discursividade do brincar funcionar como verdade, como "o conjunto das regras segundo as quais se distingue o verdadeiro do falso e se atribui ao verdadeiro, efeitos específicos de poder" (FOUCAULT, 2015, p. 53). O termo "poder" é aqui utilizado para designar "relações entre parceiros" (FOUCAULT, 1995, p. 240), como um conjunto de ações que determinam a posição dos sujeitos do brincar com a bola, objeto masculinizado, induzindo e respondendo a outro parceiro não representado, o feminino, o seu lugar possível: não sujeito do futebol.

A forma textual singularizada em "Raul é um menino que adora brincar" (Figura 1) não exclui as imagens desejáveis discursivamente, aos sujeitos do feminino, pois "cada exemplo de uma imagem ou nome ou pronome masculino invoca a ausência do outro, que é o feminino" (DOWLING, 1991, p. 3, tradução nossa). Assim, o currículo-brinquedo de matemática faz circular o sujeito do feminino desejável, que não é excluído do brincar, mas comunica nas imagens, sua ausência na capacidade objetiva de jogar futebol ou mesmo de inventar "truques" com o conhecimento matemático.

O masculino não é o sujeito unificado e centralizado do brincar com a bola, pois foram registradas 155 imagens de meninos e somente 35 de meninas interagindo com a bola, portanto, há uma predominância das representações masculinizadas para o futebol, além de essas imagens apresentarem uma postura plástica mais dinâmica para o brincar com a bola, em relação a postura do sujeito do feminino. 
Figura 2 - Brincar com a bola.

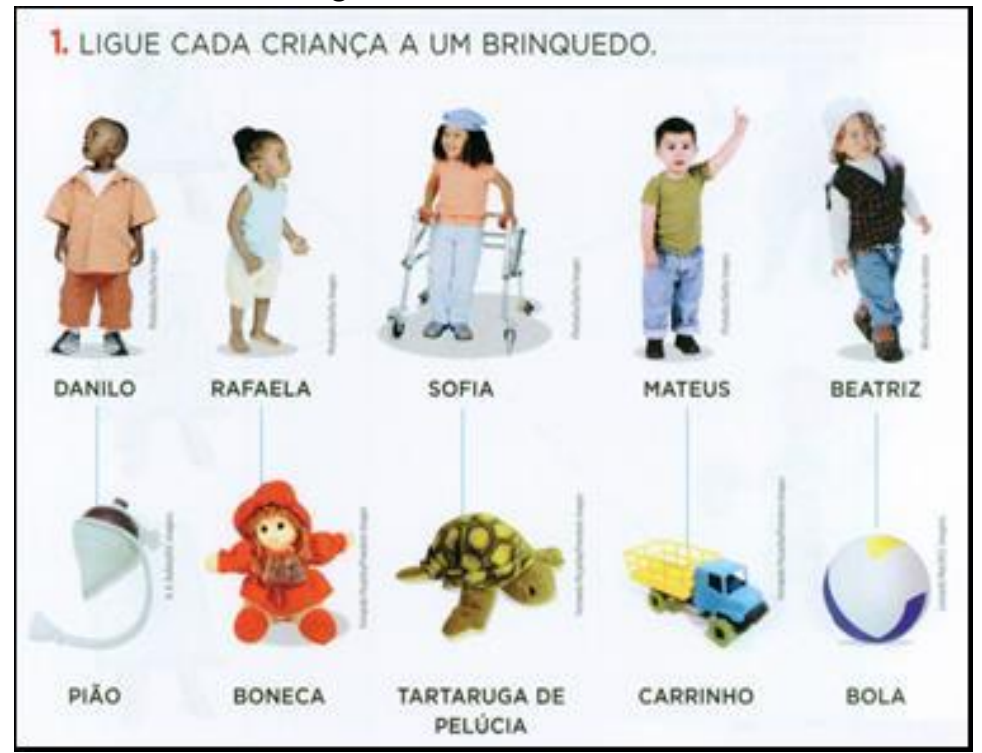

Fonte: Santos; Ribeiro; Pessôa, 2014, p. 49.

O sujeito do feminino, do brincar com a bola, vinculado na imagem do currículo (figura 2), é um sujeito "criança". Portanto, não generificado como o sujeito da identidade masculinizada fixada do futebol, dos uniformes de times, das chuteiras e das atitudes corporais atléticas como representada na figura 1, excluindo as imagens do feminino, que está ligado a bola (figura 2), o próprio feminino do futebol.

O brincar e a bola, materializados no currículo de matemática de maneira singularizada, funcionam como instrumentos pedagógicos na constituição ativa dos processos de subjetividade dos sujeitos que brincam (BUJES, 2000). O currículo-brinquedo controla e regula os sujeitos que brincam e funcionam como uma pedagogia cultural dos comportamentos de meninos e meninas, regulando tanto o sujeito feminino que brinca na plasticidade de uma postura marcada pela diferenciação do caráter do objeto: bola-passividade; como também, o caráter do mesmo objeto deslocado aos sujeitos masculinos que brincam: bola-esporte-atividade-dinamicidade...

Com isso, as subjetividades dos sujeitos que brincam no currículo são aprisionadas no "brinquedo e de forma correlata nas brincadeiras, enquanto manifestações da cultura vivida, estão envolvidos no processo de produção e imposição de significados" (BUJES, 2000, p. 206) sobre seus papeis no contexto social.

A figura 3 apresenta parte da atividade que tem por objetivo ensinar as crianças sobre horários de hábitos diários, como acordar, fazer as refeições, ir para a escola. A menina pensa (não fala!) e conclui, por intermédio do tempo que tem para brincar, qual horário ela terá que mudar de atividade. Mesmo que a atividade seja justificada pelo desejo da criança de maximizar o tempo de brincadeira, assim como o menino da figura 1, a construção discursiva em torno da menina na figura 3 é diferente, pois não há truque matemático que exige capacidade de fazer cálculo mental. A garota apenas realiza uma subtração simples para concluir quando terá que parar de brincar. Em outras palavras, o garoto da figura 1 usava a matemática para maximizar o tempo da brincadeira; a garota da figura 3 usa a matemática para se preocupar com o horário no qual precisa parar de brincar. Há uma evidente ligação entre uso da matemática para ensinar como ter responsabilidade. 
Figura 3 - Hora para brincar.

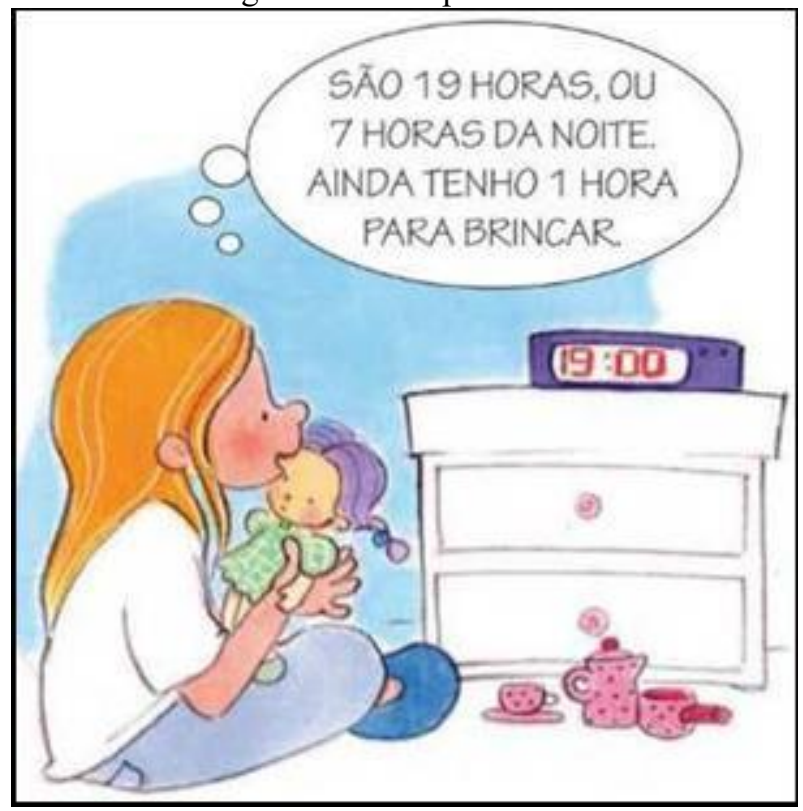

Fonte: Nani, 2014, p. 227.

Além disso, as imagens de meninas, como sujeitos que brincam com objetos que exigem uma postura passiva e delicada para o cuidado futuro com a casa e os filhos, fazem parte de uma pedagógica para além dos processos que envolvem técnicas e o desenvolvimento de habilidades neutras internas ao conhecimento matemático. Na contramão desse pensamento, o currículobrinquedo é pensado na projeção em meio a relações de poder para fazer perpetuar sujeitos construídos na cultura, contingente, mas tomados como históricos, do ponto de vista da continuidade, em benefício de uma estrutura fixa do social (FOUCAULT, 2013).

A pedagogia cultural do currículo-brinquedo tenta fixar e unificar identidades masculinizadas como os sujeitos do futebol, ao mesmo tempo em que ensinam aos sujeitos do feminino o seu lugar predominante no brincar com bonecas e bichinhos de pelúcia. Ainda que possam figurar nas imagens representadas do objeto brincar com a bola masculinizada, o feminino aparece no currículo como sujeito adjetivado do masculino, como no exemplo: "Sofia, irmã de Lucas, coleciona carrinhos, ela tinha 20 carrinhos e ganhou 5 em seu aniversário. Quantos carrinhos ela tem agora?" (MATRICARDI, 2014, p. 110).

O sujeito "Sofia", feminino, colecionador de carrinhos e "irmã de Lucas" (o que nos parece uma justificativa para o fato de uma menina poder colecionar carrinhos: ter um irmão!) parece funcionar como uma estratégia discursiva para mostrar que a linguagem do currículo não é reprodutora de uma prática cultural de brincadeiras no endereçamento de subjetividades generificadas, no interior da oposição hierárquica do masculino/feminino. No entanto, pode ser compreendida como um "ritual de genuflexão [ajoelhar, reverenciar] para o discurso da igualdade de oportunidades e para desarmar bombas antissexistas" (DOWLING, 1991, p. 4, tradução nossa), reforçando não as lutas sociais por igualdade, mas a própria diferenciação. Um movimento discursivo que confirma o que significa ser um sujeito do feminino e do masculino e suas possibilidades de atuação e interesses culturais. As imagens discursivas são assim, discursividades que restringem as possibilidades e atuação dos sujeitos no 
campo social, "um modo de construir sentidos que influencia e organiza tanto nossas ações quanto a concepção que temos de nós mesmos" (HALL, 2015, p. 31).

Assim, o currículo-brinquedo se localiza estrategicamente nos anos iniciais do ensino fundamental, impulsionando a formação da identidade de meninos e meninas, centrada nas representações de imagens binárias do humano, pulsando práticas discursivas do brincar, local onde se "inicia a relação da criança com os sistemas simbólicos fora dela mesma e é, assim, o momento da sua entrada nos vários sistemas de representação simbólica - incluindo a língua, a cultura e a diferença sexual" (HALL, 2015, p. 24).

Se por um lado é possível encontrar algumas discursividades em que os sujeitos femininos representam ações culturais predominante do masculino, ainda que para confirmar a subjetividade cultural e histórica do feminino, como aquele que estabelece uma relação de dependência adjetivada com o sujeito predominante da ação discursiva e, portanto, masculino; os sujeitos do masculino não são vinculados em imagens que confirmam a subjetividade feminina no currículo-brinquedo nos livros didáticos analisados. Os sujeitos da pedagógica cultural que brincam na interação com objetos e entre si são concebidos, intencionalmente por identidades fixas e estáveis (HALL, 2015) e assim, meninos não brincam com bonecas.

No movimento discursivo e simbólico, as imagens do currículo-brinquedo, podem provocar conflitos. Compreendem a relação do humano com o seu gênero como fato delimitado previamente que os qualifica, que o torna de seu gênero por meio de sua relação com as imagens simbólicas de brinquedos e brincadeiras plastificadas no currículo, "como se o gênero fosse um pós-escrito ou uma consideração cultural posterior" (BUTLER, 2016, p. 194). Assim, o gênero, como marcador cultural, fica estático e preso no masculino e feminino e passível de ser ensinado no currículo de matemática.

Sujeitos que brincam no currículo de matemática marcado pela dimensão de gênero no binário discursivo das representações dos livros didáticos atuam na construção de uma identidade aprisionada na criança-brinquedo, cria a ilusão hegeliana de expressar a vida em categorias reais. Meninos compram carrinhos e meninas compram bonecas são discursividades expressas na atividade da figura 4: "Juliana quer comprar a boneca" e "Ramon comprou a bola de futebol e pagou com 3 notas de 10 reais", são frases contidas nessa atividade, cujo objetivo é ensinar às crianças como realizar operações básicas com unidades monetárias.

Figura 4 - Brinquedo na vitrine.

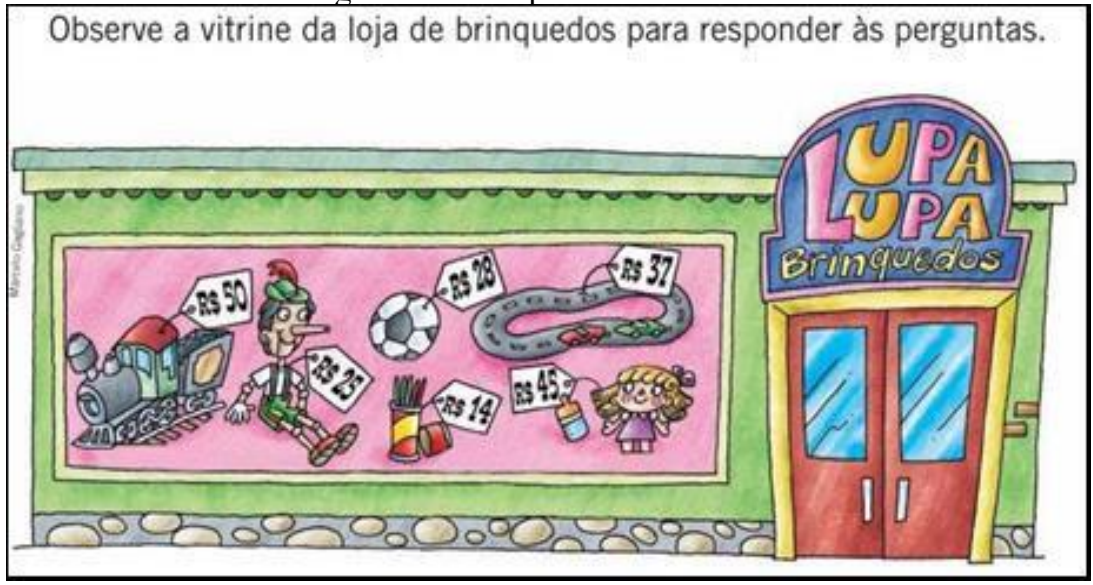

Fonte: Padovan, 2014, p. 129

Reflexão e Ação [ISSN 1982-9949]. Santa Cruz do Sul, v. 26, n. 2, p. 149-164, mai./ago. 2018. https://online.unisc.br/seer/index.php/reflex/index 
Apesar da oportunidade aparente de escolha, o brincar de bonecas é uma discursividade que confirma o feminino como sujeito que cuida do outro miniaturizado nas representações do currículobrinquedo. Portanto, como aquele que deve aprender a cuidar, ação do tempo futuro, e por isso, tantas vezes repetida no currículo de matemática nos 103 livros analisados nas imagens e nos textos do conhecimento matemático escolar.

O currículo-brinquedo comunica a tradição feminilizada das brincadeiras com bonecas, um cuidado com sujeitos miniaturizados. Tarefa do feminino, uma construção discursiva das "tarefas obrigatórias, de gestos impostos por uma tradição ou um aprendizado, de subdivisões ou de repartição" (FOUCAULT, 1995, p. 241), uma tarefa a espera do crescimento futuro.

É a miniaturização do humano, "como aquilo que permite colher e gozar a pura temporalidade contida no objeto" (AGAMBEN, 2005, p. 88) que constrói significado ao "cuidar do outro" como tarefa feminina. Transforma os significados do receber cuidados para o "cuidar do outro", um aprender as tarefas fragmentadas da vida adulta.

Figura 5 - Uma nova palavra.

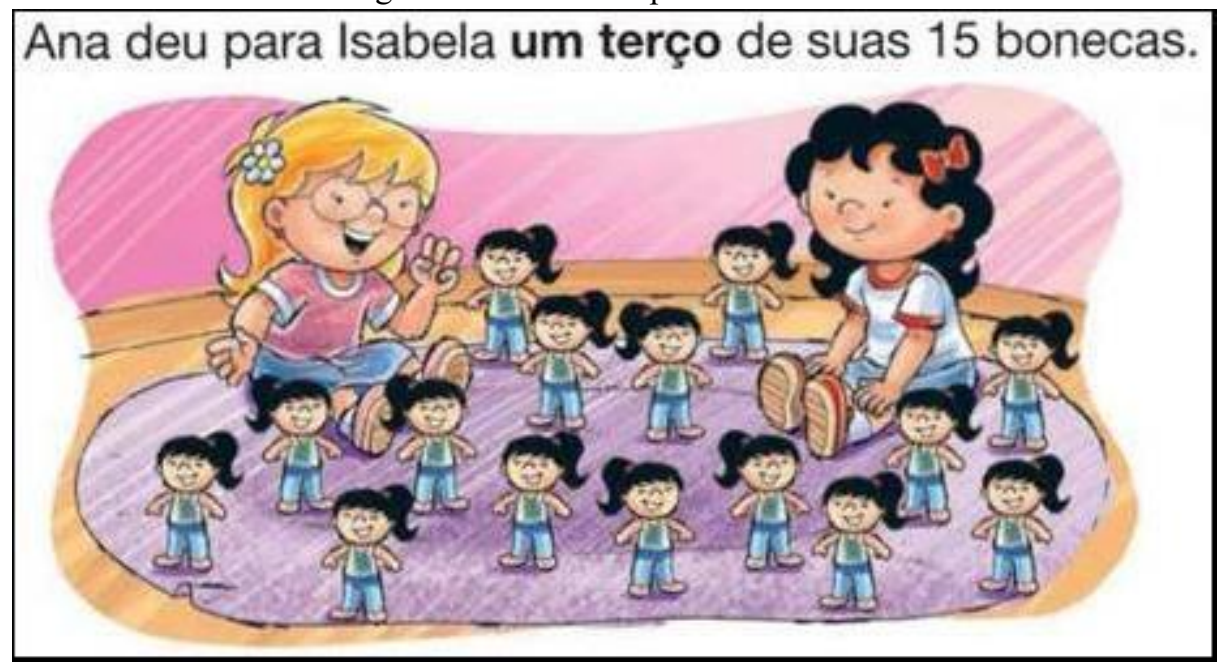

Fonte: Silveira, 2014, p. 244.

O currículo de matemática dos brinquedos e brincadeiras produz o visível do estereótipo normativo daquele que gera e cuida do outro e se constitui como uma autoridade legitimada cientificamente que impõe modos de vidas. Assim, seu fundamento se assenta no "inexperienciável" (AGAMBEN, 2005, p. 23), uma vez que na discursividade do currículo-brinquedo há um movimento incessante de exclusão localizado no binário discursivo: meninos não brincam com bonecas, meninas devem aprender a cuidar do outro (Figura 5), entre tantas outras discursividades impostas.

Em meio a essas complexas relações discursivas que regem a conduta da criança-brinquedo no currículo de matemática, os sujeitos que brincam aprendem a conduzir o outro e a se conduzirem, uma "maneira de se comportar num campo mais ou menos aberto de possibilidades" (FOUCAULT, 1995 , p. 244). Por meio da linguagem, compreendida como um sistema social impregnado de significados culturais, e não um sistema individual, os significados movimentados pelo currículo- 
brinquedo são ensinados ou intercambiados, sempre a procura de um fechamento na produção de subjetividades (HALL, 2015).

Assim, nas possibilidades discursivas em "Ramon comprou a bola de futebol e pagou com 3 notas de 10 reais" (PADOVAN, 2014, p. 129) e "Lúcia comprou uma boneca por $R \$ 55,00$ e usou apenas duas notas de real para pagá-las" (MATRICARDI, 2014, p. 136) transitam as possibilidades discursivas de atuação dos gêneros marcadas pelo currículo-brinquedo. Mas, também, fazem parte de uma rede discursiva ligada ao controle do consumo dos sujeitos que brincam, olhando para sujeitosfuturos, como aqueles que irão movimentar um mercado de brinquedos, de compra e venda.

Em meio ao movimento da cientificidade dos conhecimentos matemáticos, o currículobrinquedo produz gestos múltiplos: uma pedagogia cultural que mascara a produção de subjetividades na infância; uma prática de diferenciação localizadas nas representações de gênero como objeto para fixar identidades e regular a conduta de uns em relação a outros; e, uma estratégia neoliberal para regular um dispositivo pedagógico no currículo.

\section{DISPOSITIVO PEDAGÓGICO DO CURRÍCULO-BRINQUEDO}

São as cenas e os efeitos das vidas miniaturizadas construídas como representações do humano no currículo-brinquedo, que reproduzem vidas ligadas aos estereótipos normativos do feminino e masculino, delimitando restrições discursivas, movimentadas pelo conhecimento matemático, marcando os sujeitos em suas identidades regidas dentro de um campo binário.

O movimento de análise dessas representações nos permitiu descrever o currículo-brinquedo como um dispositivo pedagógico de um currículo reprodutor de endereçamentos de gênero. Dispositivo compreendido como "um conjunto decididamente heterogêneo que engloba discursos, instituições, organizações arquitetônicas, decisões regulamentares, leis, medidas administrativas, enunciados científicos, proposições filosóficas, morais, filantrópicas" (FOUCAULT, 2015, p. 364), o dito e o não dito de parte de uma rede, complexa e dispersa, que constitui uma verdade sobre as representações do brincar no currículo. Uma rede de relações pedagogizadas com a aprendizagem matemática, um dito nos manuais de orientação aos professores - ensinar por meio de objetivos de aprendizagens delimitados antecipadamente ao primeiro contato com as crianças. São sempre as mesmas crianças?

Uma repetição discursiva a espera de sujeitos que possam relacionar quantidades a representações numéricas, a manusear e administrar matematicamente o sistema monetário e aprender a comparar e ordenar grandezas, mas que, principalmente, aprendam que essas representações fazem sentido em um mundo de atuação delimitada entre meninos e meninas.

O não dito nos manuais aos professores é que essa é uma rede complexa, pois se articula a marcas discursivas do campo da [E]educação que busca pela incessante tarefa de tornar a atividade do conhecimento matemático mais interessante para os alunos. Uma tarefa de quase esgotamento essa busca pelo "interessante" no currículo, nem sempre presente e possível no conhecimento matemático, mas provocadas nas representações do currículo-brinquedo: o fazer brincar como 
imperativo da atividade docente. Um lugar à espera dos professores que ensinam matemática nos anos iniciais do ensino fundamental.

As possibilidades de atrair a atenção da criança fazem com que as representações de brinquedos e brincadeiras no currículo de matemática se constituam como elos desse dispositivo pedagógico que é o currículo-brinquedo. É como se o conhecimento passasse a se articular com elementos heterogêneos e dispersos e por isso, tão complexa é sua constituição e seu desmembramento, quanto seu desmascaramento. Para Foucault (2015), a heterogeneidade é um "elemento que permite justificar e mascarar uma prática que permanece muda" (p. 364), como na ideia de que a aprendizagem se torna mais interessante para as crianças ou ainda, brincar desenvolve a socialização das crianças. Tantas outras reinterpretações podem ser disparadas a partir das representações de brinquedos e brincadeiras no currículo, ou seja, "entre esses elementos, discursivos ou não, existe um tipo de jogo" (ib., p. 364) do interessante, do atrativo e do sedutor.

Também, o dispositivo pedagógico do currículo-brinquedo como "um tipo de formação que, em um determinado momento histórico, teve como função principal responder a uma urgência" seja a de tornar interessante a escolarização do conhecimento matemático para as crianças e assim, precisou, antes disso, se voltar ao mundo da criança. Até o início do século XVII os objetos miniaturizados como as bonecas faziam parte do cenário de adultos, objetos de decoração (BUJES, 2000), que hoje pedagogizados, foram modificados e assumiram posições particulares no currículo, tornando-o objeto atrativo de desejo.

O dispositivo pedagógico do currículo-brinquedo tem então "uma função estratégica e dominante" (FOUCAULT, 2015, p. 365). Tanto produz e reproduz posições discursivas como a demarcação de estereótipos de gênero, como absorve ou faz flutuante, no currículo de matemática, uma população que a sociedade cristã acha incômoda: todas as representações de gênero que não se localizam no binário discursivo menino ou menina. Para Foucault (2015), isto faz do dispositivo pedagógico do currículo-brinquedo um dispositivo de controle e de dominação das representações de gênero do campo social, um imperativo estratégico que funciona como matriz da vida possível no currículo de matemática. Uma subjetividade construída e repetida para meninos e meninas do humano possível dentro e fora da escola.

As imagens de brinquedos e brincadeiras articuladas ao conhecimento matemático compõem o dispositivo pedagógico. Entretanto, mais do que intencionar aprendizagens, por meio de representações do currículo-brinquedo, impulsiona o mascaramento de uma prática discursiva que permanece muda no currículo de matemática. Qualifica os corpos que brincam como corpos humanos, pois se localizam estritamente no binário discursivo, atuando por um princípio de exclusão de um em relação ao outro. Ainda, o dispositivo pedagógico do currículo-brinquedo, reprodutor de endereçamentos de gênero, exclui outras representações corporais que não se encaixam no binário discursivo (BUTLER, 2016) e assim, não fazem parte do currículo-brinquedo.

Nessa rede de elementos discursivos do dispositivo pedagógico do currículo-brinquedo, em um primeiro momento é possível demarcar a predominância do objetivo estratégico para despertar o interesse para o conhecimento matemático e no momento em que se constitui como verdade no campo da Educação Matemática, engloba um duplo processo: primeiro a constituição discursiva em torno do 
brinquedo e das brincadeiras como imperativo ao conhecimento matemático e a propostas de atividades dos professores que ensinam matemática nos anos iniciais, gera uma produção em torno dessa temática nos manuais de orientação do trabalho didático com as atividades matemáticas. Há em torno disso, uma orientação de leituras recomendadas aos professores e aos alunos - o brincar como currículo. Essa construção discursiva impõe tanto efeitos chamados de "negativos" quanto de "positivos": professores que conseguem diversificar as atividades de aprendizagens e os que não conseguem. Movimento discursivo que implica toda uma arquitetura para a constituição de um perfil ideal de professor que faz o currículo brincar, e tantas ressonâncias mais na vida docente atravessada por esse objetivo estratégico.

Por outro lado, esse objetivo produz efeitos na vida de crianças que brincam - a constituição de uma vida aprisionada nas imagens de gênero movimentadas no currículo. Uma reutilização das formas de habitar o humano. O gênero - como nos sentimos e como somos, passou a ser reutilizado não só nos discursos religiosos, como também, nas finalidades políticas do campo da educação atravessado pela economia. O currículo-brinquedo vende! Objetos e vidas.

\section{REFERÊNCIAS}

1. AGAMBEN, G. Infância e história: destruição da experiência e origem da história. Tradução Henrique Burigo. Belo Horizonte: Editora UFMS, 2005.

2. BRASIL. Lei de Diretrizes e Bases da Educação Nacional. Lei número 9394, 20 de dezembro de 1996. Ministério da Educação - MEC. Secretaria de Educação Básica. Guia de livros didáticos: PNLD 2016 - Alfabetização Matemática e Matemática: ensino fundamental anos iniciais. Brasília: Ministério da Educação, Secretaria de Educação Básica - MEC/SEB, 2015.

4. BUJES, M. I. Criança e brinquedo: feitos um para o outro? In: COSTA, M. V. (Org.). Estudos Culturais em Educação. Porto Alegre: Editora da UFRGS, 2000, p. 205-228.

5. BUTLER, Judith. Problemas de gênero: feminismo e subversão da identidade. Rio de Janeiro: Civilização Brasileira, 2016.

6. DOWLING, P. Gender, Class, and Subjectivity in Mathematics: A Critique of Humpty Dumpty. For the Learning of Mathematics, v. 11, n. 1, 1991, p. 2-8. Published by: FLM Publishing Association. 
7. FONSECA, Maria da Conceição Ferreira Reis; SOUZA, Maria Celeste Reis Fernandes de.

Relações de gênero, Educação Matemática e discurso: enunciados sobre homens, mulheres e matemática. Belo Horizonte: Autêntica Editora, 2010.

8. FOUCAULT, M. A arqueologia do saber. Tradução de Luiz Felipe Baeta Neves. - 8. ed. - Rio de Janeiro: Forense Universitária, 2013. As palavras e as coisas: uma arqueologia das ciências humanas. São Paulo: Martins Fontes, 1999.

10. 11 . trajetória filosófica: para além do estruturalismo e da hermenêutica. Rio de Janeiro: Forense universitária, 1995, p. 231-249.

13. GRANDO, R. C. O conhecimento matemático e o uso de jogos na sala de aula. 2000. $239 \mathrm{f}$. Tese (Doutorado em Educação) - Faculdade de Educação, Universidade Estadual de Campinas, Campinas, 2000.

14. HALL, S. A identidade cultural na pós-modernidade. Rio de Janeiro: Lamparina, 2015. 15. Educação \& Realidade, 1997, v. 22, nº 2, jul./dez.

16. HANNA, G. Towards gender equity in mathematics education: An ICMI study. New York, Boston, Dordrecht, London, Moscow: Kluver Academic Publishers, 1996. (New ICMI Studies Series).

17. LEDER, G. Educational Studies in Mathematics, v, 28, n. 3, p. 195-198. Guest Editorial, 1995.

LONGEN, A. Projeto Jimboê: alfabetização matemática. São Paulo: Editora do Brasil, 2014, v. 3, $3^{\circ}$ ano, 2014.

19. MATRICARDI, C. (org.). Projeto Lumirá: alfabetização matemática. São Paulo: Editora Ática, v. 2, $2^{\circ}$ ano, 2014.

20. NANI, A. P. S. (org.). Aprender juntos: alfabetização matemática. São Paulo: Edições SM, v. 2, 2 ano, 2014. 
21. PADOVAN, D. Ligados.com: alfabetização matemática. São Paulo: Saraiva, v. 2, 2014.

22. POPKEWITZ, T. The Alchemy of the Mathematics Curriculum: Inscriptions and the Fabrication of the Child. American Educational Research Journal, v. 41, n. 1, p. 3-34, 2004.

SANTOS, F. V. dos; RIBEIRO, J. da S.; PESSÔA, K. A. A escola é nossa: alfabetização matemática. São Paulo: Scipione, v. 1, 2014.

SARTORI, A. S. T.; DUARTE, C. G. O sujeito lúdico produzido pela/na educação matemática: interlocuções com o neoliberalismo. Bolema: Boletim de Educação Matemática, v. 31, n. 57, p. 53-67, abr. 2017. Práticas lúdicas na educação matemática escolar: a escola nos fluídos da modernidade líquida. Educação Matemática Pesquisa, v. 17, n. 2, p. 216-231, 21 ago. 2015.

26. SILVA, M. A; MIARKA, R. Geni, a pesquisa em [E]educação [M]matemática e o zepelim. Perspectivas da Educação Matemática, v. 10, n. 24, p. 752-767, 2017.

27. SILVEIRA, E. Projeto navegar: matemática. São Paulo: Moderna, v. 2, 2014. SOUZA, D. M. X. B.; SILVA, M. A. Questões de gênero no currículo de matemática: atividades do livro didático. Educação Matemática Pesquisa, v. 19, n. 3, p. 374-392, 2017.

29. WALSHAW, M. et al, Beyond the box: rethinking gender in mathematics education. (A. Chronaki, Org.). In: Proceedings of the ninth international mathematics education and society conference MES9. Volos, Greece: University of Thessaly Pess, 2017.

30. VEIGA-NETO, A. Michel Foucault e os Estudos Culturais. In: COSTA, Marisa Vorraber (org.). Estudos Culturais em Educação. Porto Alegre: Editora da UFRGS, 2000, p. 37-69. 


\section{Deise Maria Xavier de Barros Souza:}

Doutoranda no Programa de Pós-Graduação em Educação Matemática da Universidade Federal de Mato Grosso do Sul (UFMS).

\section{Marcio Antonio da Silva}

Doutor em Educação Matemática pela Pontifícia Universidade Católica de São Paulo (PUC/SP). Professor do Instituto de Matemática e do Programa de Pós-Graduação em Educação Matemática da Universidade Federal de Mato Grosso do Sul (UFMS), Campo Grande/MS, Brasil. Líder do GPCEM (Grupo de Pesquisa Currículo e Educação Matemática).

\section{Como citar este documento:}

SOUZA, Deise Maria Xavier de Barros; SILVA, Marcio Antonio da. O dispositivo pedagógico do currículo-brinquedo de matemática, marcado pela dimensão de gênero, na produção de subjetividades. Reflexão e Ação, Santa Cruz do Sul, v. 26, n. 2, ago. 2018. ISSN 1982-9949. Disponível em: <https://online.unisc.br/seer/index.php/reflex/article/view/11747>. Acesso em: ___. doi: http://dx.doi.org/10.17058/rea.v26i2.11747. 